\title{
Analysis of facial bone fractures: An 11-year study of 2,094 patients
}

\author{
Kun Hwang ${ }^{1,2}$, Sun Hye You ${ }^{1}$ \\ ${ }^{1}$ Department of Plastic Surgery and ${ }^{2}$ Center for Advanced Medical Education by BK21 Project, Inha University College of \\ Medicine, Incheon, Korea
}

Address for correspondence: Dr. Kun Hwang, Department of Plastic Surgery and Center for Advanced Medical Education by BK21 Project, Inha University College of Medicine, 7-206 Sinheung-dong, Jung-gu, Incheon - 400-711, Korea. E-mail: jokerhg@inha.ac.kr

\section{ABSTRACT}

Purpose: The medical records of these patients were reviewed and analysed to determine the clinical characteristics and treatment of facial bone fractures. Patients and Methods: This is a retrospective study of 2,094 patients with facial bone fractures from various accidents that were treated at the Inha University Hospital from 1996 to 2007. Results: The most common age group was the third decade of life (29\%). Males were more common than females (3.98:1). The most common aetiology was violent assault or nonviolent traumatic injury (49.4\%). The most common isolated fracture site was the nasal bone $(37.7 \%)$, followed by the mandible $(30 \%)$, orbital bones $(7.6 \%)$, zygoma $(5.7 \%)$, maxilla $(1.3 \%)$ and the frontal bone $(0.3 \%)$. The largest group with complex fractures included the inferior region of the orbital floor and zygomaticomaxilla (14\%). Closed reduction was performed in $46.3 \%$ of the cases while $39.7 \%$ of the cases required open reduction. For open reductions, the most commonly used soft-tissue approach was the intraoral approach $(32.3 \%)$. The complication rate was $6.4 \%$ and the most common complication was hypoesthesia $(68.4 \%)$ followed by diplopia $(25.6 \%)$. Conclusion: Long-term collection of epidemiological data regarding facial fractures and concomitant injuries is important for the evaluation of existing preventive measures and useful in the development of new methods of injury prevention and treatment.

\section{KEY WORDS}

Facial bones; facial fractures; injury prevention; treatment

\section{INTRODUCTION}

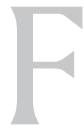
acial injuries occur in a significant proportion of trauma patients requiring prompt diagnosis of fractures and soft tissue injuries, with possible emergency interventions. ${ }^{[1]}$ Each year, increasing numbers of patients are admitted to the hospital with facial trauma. ${ }^{[1]}$ There are many studies in the literature that have analysed the demographic factors associated with facial trauma according to various criteria. ${ }^{[2-4]}$ The epidemiology of facial fractures varies with regard to injury type, severity and cause, depending on the population studied..$^{[5]}$ The differences in the populations with regard to the causes of facial fractures may be the result of differences in culture and a variety of risk factors. However, the reports on patients studied, use the severity of the injury as the major selection criteria for epidemiological investigation. ${ }^{[5]}$

An understanding of the cause, severity and temporal distribution of facial trauma can aid in establishing clinical and research priorities for effective treatment and prevention of these injuries. ${ }^{[5]}$ Continuous long-term collection of data regarding the epidemiology of facial 
fractures is important because it provides information necessary for the development and evaluation of preventive measures that might help reduce the incidence of facial injuries. ${ }^{[5]}$

The purpose of this study was to report on the natural history of facial injuries in 2,094 cases over 11 years at the Department of Plastic and Reconstructive Surgery, Inha University Hospital, Incheon, South Korea.

\section{MATERIAL AND METHODS}

The medical records of patients seeking treatment for facial trauma were reviewed at the Department of Plastic and Reconstructive Surgery, Inha University Hospital, Incheon, South Korea. The study population consisted of 2,094 severely injured patients with facial fractures from February 1996 to April 2007, who were admitted to our hospital for operation and conservative treatment. The parameters assessed were age, gender, time of injury, aetiology and associated injuries, in addition to the type of fracture and treatment offered. The facial bone fractures were classified as isolated or complex fractures. The isolated facial bone fractures included frontal bone, orbital bone, nasal bone, maxilla, zygoma and mandible. The complex fractures were subclassified into five types according to the anatomical direction from the orbit and the extension from an adjacent area, which were superior, medial, lateral, inferior or other locations [Table 1]. In addition, the complications and prognoses were analysed.

\section{RESULTS}

\section{Demographic distribution}

This retrospective study of 2,094 cases included 1,673 males and 421 females, aged 1-97 years (mean age $=30.6$ years) with facial bone fractures [Table 2]. The highest frequency of facial bone fractures was in the age group 21-30 years $(n=608,29 \%)$, followed by $11-20$ years $(n=466,22.3 \%)$ and $31-40$ years $(n=439,21 \%)$ [Table 2]. There was a significant male predominance in all age groups and the overall ratio of males to females was 3.98:1.

The analysis of the annual incidence revealed that both the absolute number and the proportion of facial injuries peaked in 2006 [Table 3], with slight increases every year [Table 3]. The monthly incidence was relatively even;
Table 1: Classification of facial bone fractures

\begin{tabular}{|c|c|c|c|c|}
\hline Fracture & Types & Locations & Cases & $\%$ \\
\hline \multirow[t]{21}{*}{ Isolated } & & & 1,720 & 82.1 \\
\hline & Frontal bone & & 7 & 0.3 \\
\hline & Orbital bone & & 159 & 7.6 \\
\hline & & Floor & 95 & 4.5 \\
\hline & & Medial wall & 42 & 2.0 \\
\hline & & Roof & 4 & 0.2 \\
\hline & & Lateral wall & 3 & 0.1 \\
\hline & & Combined & 15 & 0.7 \\
\hline & Nasal bone & & 790 & 37.7 \\
\hline & Maxilla & & 27 & 1.3 \\
\hline & Zygoma & & 119 & 5.7 \\
\hline & & Zygomatic arch & 77 & 3.7 \\
\hline & & Zygomaticomaxilla & 42 & 2.0 \\
\hline & & $\begin{array}{l}\text { Zygomaticofrontal } \\
\text { bone }\end{array}$ & 0 & 0 \\
\hline & Mandible & & 618 & 30.0 \\
\hline & & Angle & 149 & 7.1 \\
\hline & & $\begin{array}{l}\text { Symphysis or } \\
\text { parasymphysis }\end{array}$ & 143 & 6.8 \\
\hline & & Condyle & 70 & 3.3 \\
\hline & & Body & 26 & 1.2 \\
\hline & & Ramus & 3 & 0.1 \\
\hline & & Combined & 227 & 10.8 \\
\hline \multirow[t]{15}{*}{ Complex } & & & 374 & 17.9 \\
\hline & Superior & & 6 & 0.2 \\
\hline & & $\begin{array}{l}\text { Frontal and orbital } \\
\text { roof }\end{array}$ & 1 & 0 \\
\hline & & $\begin{array}{l}\text { Frontal, orbital roof } \\
\text { and nasal bone }\end{array}$ & 5 & 0.2 \\
\hline & Medial & & 16 & 0.8 \\
\hline & & $\begin{array}{l}\text { Orbit medial wall } \\
\text { and nasal bone }\end{array}$ & 16 & 0.8 \\
\hline & Lateral & & 4 & 0.2 \\
\hline & & $\begin{array}{l}\text { Orbit lateral wall and } \\
\text { zygomatic arch }\end{array}$ & 4 & 0.2 \\
\hline & Inferior & & 293 & 14.0 \\
\hline & & $\begin{array}{l}\text { Zygomaticomaxilla } \\
\text { and orbital floor }\end{array}$ & 66 & 3.2 \\
\hline & & $\begin{array}{l}\text { Zygomaticomaxilla, } \\
\text { orbital floor and } \\
\text { nasal bone }\end{array}$ & 42 & 2.0 \\
\hline & & $\begin{array}{l}\text { Orbital floor and } \\
\text { nasal bone }\end{array}$ & 17 & 0.8 \\
\hline & & Tripod & 130 & 6.2 \\
\hline & & $\begin{array}{l}\text { Zygomatic and } \\
\text { nasal bone }\end{array}$ & 38 & 1.8 \\
\hline & Others & & 55 & 2.7 \\
\hline
\end{tabular}

however, facial fractures were slightly more common during the month of September $(n=209,10 \%)$ [Table 4].

The most common causes of the injury were violent assault or nonviolent traumatic injury $(n=1,034,49.4 \%)$, slip or fall $(n=304,14.5 \%)$, road traffic accidents $(n=$ $303,14.5 \%)$, sports $(n=236,11.3 \%)$, work-related injuries 
Table 2: Distribution according to age and gender

\begin{tabular}{lccc}
\hline Age & Male & Female & Cases (\%) \\
\hline $0-10$ & 64 & 31 & $95(4.5)$ \\
$11-20$ & 396 & 70 & $466(22.3)$ \\
$21-30$ & 188 & 120 & $608(29.0)$ \\
$31-40$ & 349 & 90 & $439(21.0)$ \\
$41-50$ & 222 & 73 & $295(14.1)$ \\
$51-60$ & 94 & 21 & $115(5.5)$ \\
$>60$ & 60 & 16 & $76(3.6)$ \\
Total cases (\%) & $1,673(79.9)$ & $421(20.1)$ & $2,094(100)$ \\
\hline
\end{tabular}

$(n=159,7.6 \%)$ and others $(n=58,2.8 \%)$ [Table 5]. The most common sports associated with injury was soccer (38.1\%).

In $60(2.9 \%)$ of the 2,094 patients, the facial fractures were associated with other injuries [Table 6]. Head and neck injuries were the most common isolated injuries associated with facial fractures (13.3\%) [Table 6]. Among the patients with injuries to the head and neck area, most had intra cranial injuries with altered levels of consciousness, cervical spine injuries, or optic nerve injury. Some patients (1.3\%) had more than one type of associated injury, including other bone fractures [Table 7]. The most common isolated fracture associated with facial fractures was a skull fracture (22.2\%) [Table 7]. In $359(17.1 \%)$ of the 2,094 patients, the facial fractures were associated with other soft tissue injuries [Table 8]. The associated injuries were most commonly soft tissue injuries of the face and neck (89.4\%) [Table 8].

\section{Classification of facial bone fractures and treatment}

The great majority of cases were isolated injuries $(n=$ $1720,82.1 \%$ ) [Table 1]. Nasal bone fractures were the most common $(n=790,37.7 \%)$, followed by mandible fractures $(n=618,30 \%)$ [Table 1, Figure 1]. Tripod fractures were the most common type of complex injuries $(n=130$, 6.2\%) [Table 1]. For complex injuries, the inferior region had the highest frequency of fractures $(n=293,14 \%)$ [Table 1, Figure 2].

A closed reduction procedure was performed in $46.3 \%$ of the cases, open reduction in $39.7 \%$, closed and open reduction in $6.5 \%$ and no surgical intervention in $7.4 \%$ [Table 9]. The closed reduction procedure was most commonly performed for nasal bone fractures (93\%). Most of the other facial bone fractures were treated by open reduction $(39.7 \%)$ procedures. The facial bone reduction
Table 3: Annual incidence

\begin{tabular}{lcc}
\hline Year & Cases & $\%$ \\
\hline $1996.2 \sim$ & 64 & 3.1 \\
1997 & 163 & 7.8 \\
1998 & 155 & 7.4 \\
1999 & 156 & 7.5 \\
2000 & 177 & 8.5 \\
2001 & 242 & 11.6 \\
2002 & 219 & 10.5 \\
2003 & 214 & 10.2 \\
2004 & 184 & 8.8 \\
2005 & 217 & 10.4 \\
2006 & 271 & 12.9 \\
$\sim 2007.4$ & 32 & 1.5 \\
Total & 2,094 & 100 \\
\hline
\end{tabular}

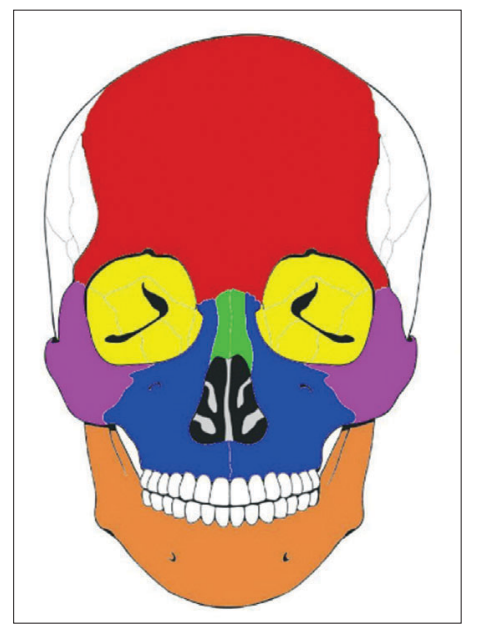

Figure 1: The skeletal region of isolated facial bone fractures: red, frontal bone $(0.4 \%)$; yellow, orbital bone $(9.2 \%)$; green, nasal bone ( $45.9 \%)$; blue, maxilla (1.6\%); purple, zygoma (6.9\%); orange, mandible (35.9\%)

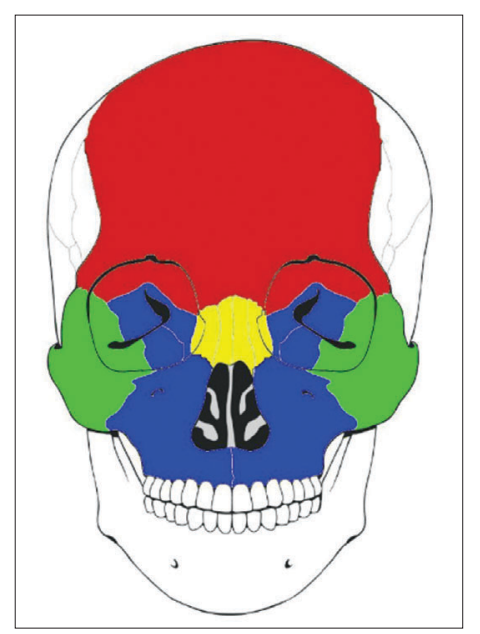

Figure 2: The skeletal region of complex facial bone fractures: red, superior (1.6\%); yellow, medial (4.3\%); green, lateral (1.1\%); blue, inferior $(78.3 \%)$ 
Table 4: Monthly distribution

\begin{tabular}{lcc}
\hline Month & Cases & $\%$ \\
\hline 1 & 148 & 7.1 \\
2 & 142 & 6.8 \\
3 & 172 & 8.2 \\
4 & 161 & 7.7 \\
5 & 191 & 9.1 \\
6 & 179 & 8.5 \\
7 & 169 & 8.1 \\
8 & 141 & 6.7 \\
9 & 209 & 10.0 \\
10 & 203 & 9.7 \\
11 & 184 & 8.8 \\
12 & 195 & 9.3 \\
Total & 2,094 & 100 \\
\hline
\end{tabular}

Table 6: Associated injuries

\begin{tabular}{lcc}
\hline Associated Injuries & Cases & $\%$ \\
\hline Head and neck & 5 & 13.3 \\
Trunk & 5 & 8.3 \\
Lower extremity & 4 & 6.7 \\
Upper extremity & 2 & 3.3 \\
Combined & 41 & 68.3 \\
Total & 60 & 100 \\
\hline
\end{tabular}

Table 8: Associated soft tissue injuries

\begin{tabular}{lcc}
\hline Associated soft tissue injuries & Cases & $\%$ \\
\hline Face and neck & 321 & 89.4 \\
Scalp & 5 & 1.4 \\
Upper extremity & 3 & 0.8 \\
Lower extremity & 3 & 0.8 \\
Trunk & 1 & 0.3 \\
Combined & 25 & 7.0 \\
Others & 1 & 0.3 \\
Total & 359 & 100 \\
\hline
\end{tabular}

was carried out on average 5.2 days post injury, and most had surgery within 1 week (72\%) [Table 10]. The average hospital stay for the patients with a facial bone fracture was 8.4 days; most were discharged from the hospital within 2 weeks $(88.5 \%)$ [Table 11 ].

For the open reduction procedure, various soft-tissue approaches were used to meet the requirements of adequate fracture exposure and stabilisation at multiple points. The most commonly used approach was the intraoral approach (32.3\%), followed by the subcilliary approach (25.3\%) [Table 12]. Fracture stabilisation materials for fixation included the miniplate (66\%), microplate $(21.7 \%)$, microplate in combination with the miniplate $(9.2 \%)$, a resorbable plate $(2.4 \%)$ and wire $(0.8 \%)$
Table 5: Causes of facial bone fractures

\begin{tabular}{lcc}
\hline Causes & Cases & $\%$ \\
\hline Trauma & 1,034 & 49.4 \\
Violence(-): injury & 556 & 26.6 \\
Violence(+): assault & 478 & 22.8 \\
Slip or fall & 304 & 14.5 \\
Traffic accident & 303 & 14.5 \\
Sport & 236 & 11.3 \\
Work related & 159 & 7.6 \\
Others & 58 & 2.8 \\
Total & 2,094 & 100 \\
\hline
\end{tabular}

Table 7: Associated bone fractures

\begin{tabular}{lcc}
\hline Associated bone fractures & Cases & $\%$ \\
\hline Skull & 6 & 22.2 \\
Upper extremity & 5 & 18.5 \\
Clavicle & 4 & 14.8 \\
Spine & 2 & 7.4 \\
Rib & 1 & 3.7 \\
Lower extremity & 1 & 3.7 \\
Pelvis & 1 & 3.7 \\
Combined & 6 & 22.2 \\
Others & 1 & 3.7 \\
Total & 27 & 100 \\
\hline
\end{tabular}

[Table 13]. In addition, reconstruction materials included the Medpor (81.5\%), a resorbable sheet (16.8\%) and bone grafts (1.7\%) [Table 14].

\section{Complications and prognosis}

The complication rate was $6.4 \%$ and the most common complication was hypoesthesia $(68.4 \%)$, followed by diplopia (25.6\%) [Table 15]. The average follow-up period for hypoesthesia was 1.2 months and most patients (88\%) improved by 1 month, while some (12\%) required 3 months for improvement. The average follow-up period for diplopia was 2 months. Most patients improved (61\%) during the first month of follow-up and $21 \%$ improved by 3 months. Other patients required a longer time to improve (7.1\%), while some required 6-12 months.

\section{DISCUSSION}

A large number of studies have reported on the aetiology of facial trauma. ${ }^{[1,8]}$ The results of epidemiological investigations vary depending on the demographics of the population studied. Factors such as geographic region, socioeconomic status and temporal factors, including time of year and time of the study, can influence both the type and the frequency of injuries reported for a 
Table 9: Treatment modalities for facial bone fractures

\begin{tabular}{lcc}
\hline Treatment modalities & Cases & $\%$ \\
\hline Closed reduction & 969 & 46.3 \\
Open reduction & 832 & 39.7 \\
Conservative & 156 & 7.4 \\
Closed and open reduction & 137 & 6.5 \\
Total & 2,094 & 100 \\
\hline
\end{tabular}

Table 11: Days of hospitalisation

\begin{tabular}{lcc}
\hline Weeks & Cases & $\%$ \\
\hline$<1$ & 449 & 23.2 \\
$1-2$ & 945 & 48.8 \\
$2-3$ & 485 & 25.0 \\
$3-4$ & 53 & 2.7 \\
$>4$ & 6 & 0.3 \\
Total & 1,938 & 100 \\
\hline
\end{tabular}

Table 13: Materials used for fixation

\begin{tabular}{lcc}
\hline Materials & Cases & $\%$ \\
\hline Miniplate & 445 & 66.0 \\
Microplate & 146 & 21.7 \\
Miniplate and microplate & 62 & 9.2 \\
Resorbable plate & 16 & 2.4 \\
Wire & 5 & 0.7 \\
Others & 6 & 0.9 \\
Total & 674 & 100 \\
\hline
\end{tabular}

Table 15: Complications associated with facial bone fractures

\begin{tabular}{lcc}
\hline Complications & Cases & $\%$ \\
\hline Hypoesthesia & 91 & 68.4 \\
Diplopia & 34 & 25.6 \\
Infection & 3 & 2.3 \\
Facial palsy & 3 & 2.3 \\
Haematoma & 1 & 0.8 \\
TMJ ankylosis & 1 & 0.8 \\
Total & 133 & 100 \\
\hline
\end{tabular}

given population $\cdot^{[5]}$ This makes meaningful comparisons between epidemiological reviews difficult.

The increasing prevalence of facial bone injuries emphasises the necessity for epidemiological surveys to determine optimal prevention strategies and patient management. Such data can inform care-givers the causes and incidences of facial bone fractures. The results of this study showed a high morbidity for facial injuries in the 21-30 years age group followed by the 11-20 years age group. In addition, we found a male predominance among all injuries and ages. Although the annual incidence has increased slightly every year, the monthly frequency was relatively even.
Table 10: Time interval between accident and surgical treatment for facial bone fractures

\begin{tabular}{lcc}
\hline Interval & Cases & $\%$ \\
\hline$<3$ days & 449 & 23.2 \\
$<1$ week & 945 & 48.8 \\
$<2$ weeks & 485 & 25.0 \\
$<3$ weeks & 53 & 2.7 \\
$>3$ weeks & 6 & 0.3 \\
Total & 1,938 & 100 \\
\hline
\end{tabular}

Table 12: Soft Tissue Approaches

\begin{tabular}{lcc}
\hline Soft Tissue Approaches & Cases & $\%$ \\
\hline Intraoral & 326 & 32.3 \\
Subciliary & 256 & 25.3 \\
Submandibular & 89 & 8.8 \\
Subciliary and Dingman & 82 & 8.1 \\
Gilles & 41 & 4.1 \\
Through laceration & 26 & 2.6 \\
Riston & 25 & 2.5 \\
Transconjunctival & 9 & 0.9 \\
Dingman & 6 & 0.6 \\
Bicoronal & 6 & 0.6 \\
Combined & 142 & 14.1 \\
Others & 2 & 0.2 \\
Total & 1,010 & 100 \\
\hline
\end{tabular}

Table 14: Materials used for reconstruction

\begin{tabular}{lcc}
\hline Materials & Cases & $\%$ \\
\hline Medpor & 97 & 55.7 \\
Resorbable sheet & 20 & 11.5 \\
Bone graft & 2 & 1.1 \\
Others & 5 & 2.9 \\
Total & 119 & 100 \\
\hline
\end{tabular}

The results of this survey are consistent with prior reports in Korea. ${ }^{[6,7]}$ In general, trauma is primarily a health problem among young men. However, there are differences in the causes of injury by geographic region and socioeconomic status. ${ }^{[1,5]}$ Long-term collection and analysis of epidemiologic data regarding facial fractures in severely injured patients is an important step in the evaluation of conventional preventative measures. ${ }^{[5]}$ It is also necessary to determine trends to help guide the development of new methods of injury prevention..$^{[5]}$ Our results found that violent assault or nonviolent traumatic injuries remain the leading cause of injury. The results of this study suggest that violence prevention programs concentrating on both assault and self-inflicted injury may help decrease the frequency of facial trauma resulting from intentional injuries in this population. In addition, drinking and driving campaigns require strengthening because $30.3 \%$ of the all injuries were alcohol-related in our study. 
In the present study, the most commonly fractured isolated bones were the nasal bone (37.7\%) and the mandible (30\%). Our finding agrees with previous studies in Korea. ${ }^{[13,14]}$ This is because the nose is an easy target in personal violence. The most common aetiology of injury in our study is trauma. The nose is projecting, relatively unprotected and with very little soft tissue cover. The most common complex fracture was a tripod fracture (6.2\%). The patterns of complex facial bone fractures were classified by the anatomical direction from the orbit. Such fractures can, of course, extend to involve the associated wall of the orbit or may, as in the case of the orbital roof, be an extension from an adjacent area such as the superior rim or the frontal bone. A variety of classifications have been proposed for zygomatic fractures and orbital bone fractures. In 1961, Knight and North classified zygomatic fractures by the direction of displacement on a Waters' view radiograph. ${ }^{[10]}$ They classified 120 fractures into six groups, hypothesising that the stability after reduction might be related to the direction of displacement. This classification has been found to be helpful in predicting the clinical features and necessary treatment, but it does not apply to complex facial bone fractures. Because this system is confined to the zygoma, it does not include the surrounding structures in the classification. In addition, treatment guidelines based on a simple classification of zygomatic fractures was presented by Zingg in 1992. ${ }^{[1]}$ This is a simple classification system for zygomatic fractures based on anatomic points and fracture patterns. However, it is difficult to use one description for different complex facial bone fractures. In 2002, Manolidis analysed orbital bone fractures according to the orbital rim and orbital walls. ${ }^{[12]}$ However, a more accurate classification of injury patterns, including each of these regions, might be achieved by combining the prior classifications into one simple classification to accurately describe the degree of injury to the orbit as a whole and predict the level of surgical intervention required for rigid internal fixation.

Although we may be able to use the available classifications to explain the relationship of the fracture with the surrounding structures, they cannot be applied to all complex facial bone fractures. Therefore, a novel unified classification system for facial injuries is presented here. This proposed complex facial bone fracture classification scheme provides a convenient, descriptive and reproducible method for describing fracture patterns. In our study, the complex fractures were subclassified into five types according to the anatomical direction from the orbit and extension from the adjacent areas, i.e. superior, medial, lateral, inferior and others part. Orbital skeletal injuries are frequently associated with other significant injuries. The orbital rim was considered separately as consisting of four regions, corresponding to the skeletal elements that define it: the frontal (superior), the nasoethmoidal (medial), the zygomatic (lateral) and the maxillary region (inferior). The inferior region was the most frequently involved region in a fracture, occurring in more than three-quarters of the patients $(78.3 \%)$. This occurs due to its prominent location on the face. The medial region was involved in $4.3 \%$, the superior region in $1.6 \%$ and the lateral region in $1.1 \%$ of the patients with complex facial bone fractures.

In most of the fractured facial bones, except the nasal bones $(n=1,034)$, an open reduction was performed in $64 \%$, closed reduction in $14 \%$, no surgical intervention in $12 \%$ and a closed reduction with open reduction in $11 \%$. The fractured nasal bones accounted for most of the closed reductions (93\%) and other facial bones (64\%) for open reductions. Our finding is in agreement with previous studies in Korea. ${ }^{[14,15]}$ Facial bone reduction was carried out on average 5.2 days after the injury, when the swelling decreased, and the average hospital stay was 8.4 days. Among the 969 patients treated by open reduction, 674 patients $(70 \%)$ were treated with one or more internal fixation techniques while 110 patients $(12 \%)$ were treated with reconstruction methods. The miniplate was the most common osteosynthesis method used $(66 \%)^{[9]}$ because of the advantages in both the technical requirement and the functional outcome. The functional advantages include rapid improvement and the technical advantages include ease of application, stability and biomechanical compatibility. ${ }^{[1]}$ Medpor was the most commonly used material for reconstruction surgery. Finally, hypoesthesia and diplopia were the most common complications ( $n$ $=125,94 \%)$. Most patients with these complications improved during the first month (88\%) with hypoesthesia and by the third month with diplopia $(82 \%)$.

\section{CONCLUSIONS}

The findings of this study indicated that epidemiological research of facial fractures allows the presentation patterns of the most affected individuals and the nature of their lesions to be outlined according to the region evaluated. This retrospective study documents the higher risk of fractures in younger males and assaults 
and other traumas were the commonest causes. Isolated nasal bone fractures were most common. Open reduction was performed in most fractured facial bones, except nasal bones, and hypoesthesia was the most common complication in our study. The insight into the epidemiology of facial bone fractures and associated injuries is useful not only for developing prevention strategies but also for decisions with regard to patient care, development of optimal treatment regimens and appropriate resource allocation. Furthermore, treatment evaluation and complication rate analysis permits a more realistic interpretation of how patients should be managed.

\section{REFERENCES}

1. Erol B, Tanrikulu R, Görgün B. Maxillofacial fractures: Analysis of demographic distribution and treatment in 2901 patients (25-year experience). J Craniomaxillofac Surg 2004;32:308-13.

2. Bataineh $A B$. Etiology and incidence of maxillofacial fractures in the north of Jordan. Oral Surg Oral Med Oral Pathol Oral Radiol Endod 1998;86:31-5.

3. lida S, Matsuya T. Paediatric maxillofacial fractures: Their aetiological characters and fracture patterns. J Craniomaxillofac Surg 2002;30:237-41.

4. van Hoof RF, Merkx CA, Stekelenburg EC. The different patterns of fractures of the facial skeleton in four European countries. Int J Oral Surg 1977; 6:3-11.

5. Hogg NJ, Stewart TC, Armstrong JE, Girotti MJ. Epidemiology of maxillofacial injuries at trauma hospitals in Ontario, Canada, between 1992 and 1997. J Trauma 2000;49:425-32.

6. Lee $\mathrm{JH}$, Mun $\mathrm{GH}$, Bang SI. A clinical and statistical analysis of the facial bone fractures: 7 years survey. J Korean Soc Plast Reconstr Surg 1998;25:1046-52.

7. Lim KW, Kim JC, Kim SH, Kim SH. A clinical and statistical analysis of the facial bone fractures: From 1994 to 1998. J Korean Soc Plast Reconstr Surg 1999;109:1151-9.

8. Gassner R, Tuli T, Hächl O, Rudisch A, Ulmer H. CranioMaxillofacial trauma: A 10 year review of 9,543 cases with 21,067 injuries. J Craniomaxillofac Surg 2003;31:51-61.

9. Hayter JP, Cawood JI. The functional case for miniplates in maxillofacial surgery. Int J Oral Maxillofac Surg 1993;22:91-6.

10. Knight JS, North JF. The classification of malar fractures: An analysis of displacement as a guide to treatment. Br J Plast Surg 1961;13:325-39.

11. Zingg M, Laedrach K, Chen J, Chowdhury K, Vuillemin T, Sutter $\mathrm{F}$, et al. Classification and treatment of zygomatic fractures: A review of 1,025 cases. J Oral Maxillofac Surg 1992;50:778-90.

12. Manolidis S, Weeks BH, Kirby M, Scarlett M, Hollier L. Classification and surgical management of orbital fractures: Experience with 111 orbital reconstructions. J Craniofac Surg 2002;13:726-37; discussion 738.

13. Lim KW, Kim JC, Kim SH, Kim SH. A clinical and statistical analysis of the facial bone fractures: From 1994 to 1998. J Korean Soc Plast Reconstr Surg 1999;109:1151-9.

14. Lee $\mathrm{JH}$, Mun GH, Bang SI. A clinical and statistical analysis of the facial bone fractures: 7 years survey. J Korean Soc Plast Reconstr Surg 1998;25:1046-52.

15. Kim JD, Kim TY, Chung CE. A clinical and statistical analysis of the facial bone fractures (excluding the nasal bone). J Korean Soc Plast Reconstr Surg 1992;19:38-47.

Source of Support: Nil, Conflict of Interest: None declared. 